\title{
Schipperen tussen twee rijken: $Q$ en het Romeinse gezag
}

\begin{abstract}
Author:
Mark R.C. Grundeken ${ }^{1,2}$

Affiliations:

${ }^{1}$ Faculteit Theologie en Religiewetenschappen, Katholieke Universiteit Leuven, België

${ }^{2}$ Department of New Testament Studies, University of Pretoria, South Africa

Note:

Drs. Mark R.C. Grundeken is a Ph.D. student and assistant of Prof. Dr Joseph Verheyden at the Faculty of Theology and Religious Studies, Katholieke Universiteit Leuven, Belgium (with a Ph.D. fellowship of the Research Foundation - Flanders [FWO]), who is participating in the research project 'Biblical Theology and Hermeneutics', directed by Prof. Dr Andries G. van Aarde, honorary professor in the Department of New Testament Studies of the Faculty of Theology at the University of Pretoria, South Africa. This article was initially presented at the NavNUT Conference 'Mag in die Nuwe Testament', 16-19 January 2011 at the University of Stellenbosch, South Africa.
\end{abstract}

Correspondence to: Mark Grundeken

Email: mark.grundeken@theo. kuleuven.be

Postal address:

Research Unit Biblical Studies, Sint-Michielsstraat 4-Box 3101, 3000 Leuven, Belgium

\section{Dates:}

Received: 01 May 2011 Accepted: 21 July 2011

Published: 29 Feb. 2012

C 2012. The Authors. Licensee: AOSIS OpenJournals. This work is licensed under the Creative Commons Attribution License.
Compromising between two powers: $Q$ and the Roman Empire. The study underlying this article investigated the attitude of Sayings Source $Q$ towards the Roman authorities and their representatives. It primarily aimed at contributing to scholarly discussions on the relationships between early Christianity and the Roman Empire, but it also attempted to put the research in a broader context of present-day discussions on the issue of 'church and state'. The first part of the study dealt with Q's views on the government. The second part studied Q's views on the emperor cult. The third and final part aimed at putting Q's views on the authorities and on the veneration of the emperor in the right context. It concluded that $Q$ compromises between idealism and realism. Its attitude towards the government is quite hostile. It portrays worldly power as demonic (Q 4:5-6; 11:18, 20), it regards God as the only true Lord of heaven and earth $(Q$ 10:21) and rejects the legitimacy of the imperial cult (Q 4:5-8). It fully focuses on the completion of the kingdom of God (Q 6:20; 7:28; 10:9; 11:2b). Yet, as a relatively small community ( $Q$ 10:2), the $Q$ people seem to have realised that there was no point in standing up against the Roman authorities and their representatives. Q's propagated views on Roman power are not characterised by active resistance, but by passive dissidence ( $Q$ 6:22-23, 27-32; 12:4-5). Within the context of the Roman Empire, it was better to be a realist than a revolutionist.

\section{Inleiding}

In zijn recente boek Het monotheistisch dilemma betoogt P. Cliteur, hoogleraar encyclopedie van de rechtswetenschap aan de Universiteit Leiden, dat een geweldsaspect tot de essentie van het monotheïsme behoort (Cliteur 2010; Van de Poll 2010). Volgens hem beleven joden, christenen en moslims een innerlijke strijd, omdat ze enerzijds leven in een land waar nationale wetten gelden, en anderzijds leven vanuit het idee van Gods koninkrijk waar Gods wil bepalend is. Religieuze verhalen van deze godsdiensten (Cliteur bespreekt Gen 22, Num 25 en 1 Kon 18) leggen volgens hem de norm voor het menselijk handelen bij de wil van God. Deze zogenaamde 'morele heteronomie' zou voor gelovigen vrij dwingend zijn. Het geloof in God is dan ook een gevaar voor de rechtsorde. In een interview met dagblad Trouw voegt hij hieraan toe dat de 'goddelijke bevelstheorie' in het Nieuwe Testament nergens wordt verworpen en dat dus ook het christendom aanzet tot geweld (Van de Poll 2010). Het moge duidelijk zijn dat hierbij ten onrechte geen rekening wordt gehouden met christelijke teksten die geenszins oproepen het koninkrijk van God met geweld tot stand te brengen. Bron $Q$ is hiervan een goed voorbeeld.

Het artikel dat hier voorligt, is een studie van de houding van bron $Q$ ten opzichte van het Romeinse gezag. Het eerste deel van het artikel gaat over de houding van $Q$ ten opzichte van de overheid. Het tweede deel bestudeert de visie van $Q$ op de verering van de keizer. Het derde en laatste deel beoogt de opvattingen van $Q$ over de wereldlijke macht en over de keizercultus in het juiste perspectief te plaatsen. Hierbij dient vooraf te worden opgemerkt dat de mogelijke gelaagdheid van de bron (Kloppenborg 2000) een verbinding tussen tekst en historie bemoeilijkt (Schröter 1997:60). Verder is ervoor gekozen de Critical Edition van de tekst als uitgangspunt te nemen (eds. Robinson, Hoffmann \& Kloppenborg 2001). De vraagstelling richt zich op de visie van $Q$ op de gewenste houding van gelovigen tot de toenmalige wereldlijke macht, het Romeinse Rijk. Betoogd zal worden, dat Q schippert tussen idealisme en realisme. Van een monotheïstisch dilemma is inderdaad sprake, maar niet van een gevaar voor de rechtsorde. Gods rijk mag dan het enige zijn dat er idealiter toe doet, het Romeinse Rijk was nu eenmaal de realiteit van alledag waartegen het voor $\mathrm{Q}$ ondenkbaar was in opstand te komen.

\section{Q en de wereldlijke macht}

Het wordt wel beweerd dat de houding van $Q$ ten opzichte van de overheid wordt gekenmerkt door ambivalentie, omdat de tekst enerzijds zeer kritisch is over de wereldlijke macht, maar

How to cite this article: Grundeken, M.R.C., 2012, 'Schipperen tussen twee rijken: Q en het Romeinse gezag', HTS Teologiese Studies/ Theological Studies 68(1), Art. \#1069, 8 pages. http://dx.doi.org/10.4102/hts.v68i1.1069 
anderzijds een aantal pro-Romeinse opvattingen naar voren brengt (Frenschkowski 2002:112-113). De vraag die hier centraal staat, is in hoeverre $Q$ positief of negatief tegenover het Romeinse gezag staat.

Vooropgesteld kan worden dat de meest in het oog springende passages die iets impliceren over de visie van $Q$ op het Romeinse Rijk uitermate kritisch en negatief zijn. In twee passages wordt de wereldlijke macht immers als het domein van de duivel gezien. In Q 4:5-6 wordt de macht over alle koninkrijken van de wereld, dat wil zeggen, alle politieke macht, aan de duivel toegeschreven (Lindemann 1989:98, n. 39). In $Q$ 11:18, 20 staat het koninkrijk van de duivel ('als satan tegen zichzelf verdeeld is, hoe zal zijn koninkrijk standhouden?', v. 18) tegenover het koninkrijk van God ('dan is Gods koninkrijk tot u gekomen', v. 20). De term

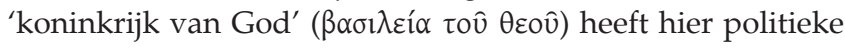
connotaties (Burchard 1998:53-54; Draper 1999:257-258; Robinson 2005:379; maar vgl. Räisänen 2001:33; Schlosser 2002:415-419; Schröter 1997:446, n. 38).

Het gegeven in $Q$ 4:5-8, 13, dat Jezus het aanbod van de duivel hem alle wereldlijke macht te geven afslaat, is door onderzoekers verschillend geïnterpreteerd. Volgens D.C. Allison (1999b:211, 213) moet Jezus' reactie gezien worden in samenhang met de 'waarschijnlijke omstandigheid' dat Jezus verwachtte koning te worden, maar op God wachtte om hem koning te maken. Anderen menen dat het verleidingsverhaal een anti-zelotische strekking heeft. Zo menen P. Hoffmann (1995:199, 204) en T. Hieke (2000:67-68) dat de passage zich richt tegen alle politieke aspiraties, dus ook tegen hen die zich tegen het Romeinse gezag verzetten en met geweld willen proberen Gods koninkrijk te realiseren. C.M. Tuckett (1992:506) heeft echter terecht opgemerkt dat de passage eerst en vooral het belang van het koninkrijk van God benadrukt door te stellen dat alle andere wereldlijke koninkrijken demonisch zijn. Anders dan L. Schottroff (1978:75-76), denkt Tuckett (1992:501, n. 102) dat de passage geen anti-Romeinse implicaties heeft. Het is, evenwel, toch aannemelijk dat de 'gedemoniseerde' wereldlijke macht in Q met het Romeinse gezag geassocieerd moet worden.

Het is verder duidelijk dat $Q$ het Romeinse gezag niet erkent. Dit kan worden afgeleid uit het gebruik van het woord 'heer' (kúplos) voor God en Jezus. De discussies omtrent het gebruik van dit woord concentreren zich op de vraag hoeveel lading men aan deze term mag toeschrijven. De vraag is, of het woord meer is dan een gewone, seculiere aanspreekvorm. Bij wijze van voorbeeld zal hier worden verwezen naar de discussie over Q 6:46, waarin Jezus zegt: 'Waarom spreken jullie me aan met "heer, heer", maar doen jullie niet wat ik zeg?' C.M. Tuckett (1996:215) is van mening dat 'heer, heer' (кúpıє kúpı) hier staat voor 'gezaghebbende leraar' (zo ook Horsley 1999a:2). M. Frenschkowski (2002:107-109) meent, daarentegen, dat het gaat om een formele acclamatie van de hemelse Jezus door de Q-gemeenschap (waarbij hij wijst op de tegenwoordige tijd van 'aanspreken', $k \alpha \lambda \varepsilon i ̂ \varepsilon \varepsilon$ ). Dat Jezus met 'heer' wordt aangesproken, betekent dat hij de toekomstige koning van Israël en de wereld is (Frenschkowski 2002:112).
Volgens Frenschkowski (2002:112) dient dit te worden verstaan tegen de achtergrond van het keizerschap van Nero, omdat vanaf die tijd 'heer' ( $k$ v́pıs) een gangbaar epitheton en metonymie voor de Romeinse keizer zou zijn geworden. Het volstaat hier te verwijzen naar een drietal teksten uit heidense, joodse en christelijke kringen die Frenschkowski (2002:98-99) aanhaalt. In de onafhankelijkheidsverklaring voor Griekenland van het jaar 67 (Syll ${ }^{3}$ 814:32) wordt keizer

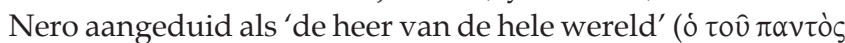
kóøuou kúpros). Josephus, Contra Apionem 2.41, bestempelt de Romeinen als 'heren van de bewoonde wereld' (кúpılo $\tau \tilde{\eta} s$

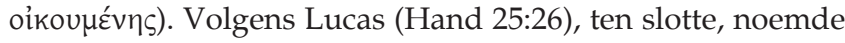
Festus keizer Nero 'de heer' (ó kúpros). Frenschkowski (2002:100) zegt hierover: 'kyrios for the emperor is part of personal piety.' Het gebruik van kúplos voor Jezus zou dus politieke en religieuze implicaties hebben.

Het betoog van Frenschkowski is op ten minste drie punten problematisch. Ten eerste wordt aan het gebruik van de aanspreekvorm kúple een vergaande en zeker niet onomstreden betekenis toegekend. Ten tweede wordt de tekst te gemakkelijk met de geschiedenis verbonden. Ten derde is de discussie over de precieze connotaties van het woord kúplos in Q niet echt nodig om iets over een eventuele politieke of religieuze achtergrond te zeggen.

Q gebruikt het woord kúproৎ namelijk direct of indirect alleen in relatie tot God of Jezus (Q 4:8, 12; 10:2, 21; «14:21»; 16:13; 19:15, 16, 18, 20 [God]; 6:46; 7:6; 9:59; 13:25 [Jezus]; 12:42, 43, 45, 46; 13:35 [God of Jezus]). Alleen God of Jezus kúpı noemen, impliceert dat anderen, dus ook de keizer, hierop geen aanspraak kunnen maken. 'Heer God' en 'Heer Jezus' zijn in $\mathrm{Q}$ geen politiek neutrale uitdrukkingen, gegeven de manier waarop Gods koninkrijk wordt afgezet tegen de koninkrijken van de wereld (Q 4:5-8; 11:18, 20) en de wijze waarop God als 'Vader, Heer van hemel en aarde' (Q 10:21) wordt aangesproken. Deze opvattingen wringen met de pretenties van de Romeinse machthebbers. De toenmalige lezers of toehoorders van de tekst zullen dit waarschijnlijk als zodanig hebben verstaan.

\section{Ook Q 16:13 wijst in deze richting:}

Niemand kan twee heren dienen. Want men zal de ene haten en de andere liefhebben, of toegewijd zijn aan de ene en de andere verachten. Jullie kunnen niet zowel God als de mammon dienen.

In engere zin betekent dit weliswaar dat gericht zijn op God en gehecht zijn aan geld of bezit onverenigbaar zijn (Piper 2000:233-234; vgl. Jacobson 2000:196), maar de algemene stelling dat niemand twee heren kan dienen heeft waarschijnlijk een bredere betekenis. Het betekent dat alleen God de Heer is die men dienen moet. Andere heren spelen geen rol van betekenis. R. Piper (1995:64-66) ziet hierin terecht een zeker wantrouwen van $Q$ naar de regerende, administrative machten. Ook Q 16:13 heeft een politieke lading.

Sommige onderzoekers menen naast deze negatieve opvattingen over de autoriteiten een aantal pro-Romeinse 
uitspraken te kunnen vinden. M. Frenschkowski (2002: 112-113) geeft hiervan twee voorbeelden. Het eerste voorbeeld betreft Q 7:1-10. Volgens Frenschkowski (2002) heeft $Q$ de aanduiding van de gelovige vreemdeling met opzet veranderd. Johannes 4:46, 49 duidt de man aan als 'hoveling' ( $\beta \alpha \sigma \imath \lambda ı$ ı́s), een koninklijke klerk. Q 7:3, 6 spreekt van een

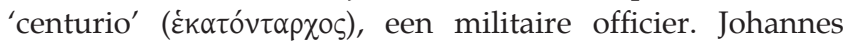
zou hier de meest oorspronkelijke lezing hebben, omdat in Jezus' tijd en enige tijd daarna geen Romeinse soldaten in Kafarnaüm aanwezig waren (Frenschkowski 2002:112). De term centurio zou dus anachronistisch zijn. Daarentegen is de lezing hoveling tegen de achtergrond van de regering van Herodes Antipas wél begrijpelijk (Frenschkowski 2002:112). De verandering in Q kan voor Frenschkowski (2002:113) maar één ding betekenen, namelijk dat $\mathrm{Q}$ een 'pro-Romeins statement' wilde maken.

Afgezien van de vraag welke lezing origineel is, hoeft de vermeende verandering, evenwel, geen pro-Romeinse verklaring te hebben. Het mag niet zonder meer worden aangenomen dat de centurio een heiden was (uit de term centurio zelf kan dit in elk geval niet worden afgeleid), ook al is dit de meerderheidspositie (bv. Theißen 1989:238). D.R. Catchpole (1993:292-308) heeft overtuigend betoogd dat de centurio in $Q$ eigenlijk iemand van Israël is. De term centurio is etnisch neutraal (Catchpole 1993:292, 307). De betekenis dient dus uit de context te worden opgemaakt. Het ligt het meest voor de hand dat Israël de setting van het verhaal is

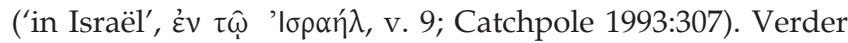
wordt Israël hier niet tegen de heidense wereld afgezet. Vers 9 betekent niet dat geloof tot dusverre in Israël afwezig was, maar dat men in Israël weliswaar tot geloof is gekomen, maar nog nooit op een dergelijke indrukwekkende wijze

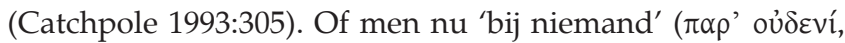
Matt) of 'zelfs niet' (oủó́, Luc) als de oorspronkelijke lezing

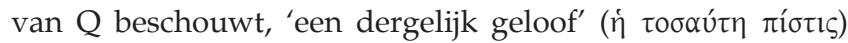
betekent geenszins dat er eerder geen enkel geloof in Israël is gevonden (Catchpole 1993:305). Wat met de centurio in Israël is gebeurd, is grootser dan wat eerder in Israël heeft plaatsgehad (Catchpole 1993:305,307). Hierbij dient te worden opgemerkt dat Matteüs en Lucas het verhaal anders hebben opgevat. Zo is de centurio volgens Lucas 7:5 een heidense Romein en impliceert Matteüs 8:11-12 dat er in Israël geen geloof was, al pretendeerde men van wel. Desondanks doet dit in principe geen afbreuk aan Catchpoles interpretatie, omdat Matteüs en Lucas de tekst mogelijk vanuit hun eigen context anders hebben opgevat dan oorspronkelijk werd bedoeld.

Bovendien benadrukt de passage juist de ondergeschiktheid van de centurio ten opzichte van Jezus (Catchpole 1993: 301-303). De centurio zegt het niet waard te zijn dat Jezus bij hem thuis komt. 'Waardig' (ikovós) en 'Heer' (кúpıos) zijn in een aantal passages in de Septuagint elkaars equivalent (vgl. Ruth 1:20-21; Job 21:15; 31:2; 39:32; Catchpole 1993: 301-302). Het gebruik í avó en kúpı in Q 7:6 dient tegen deze achtergrond te worden begrepen (Catchpole 1993:302). De centurio benadrukt zijn ondergeschiktheid ook door zichzelf

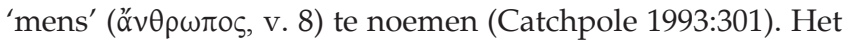
woordje 'want' ( $\gamma \alpha$ óp) in vers 8 verwijst daarbij terug naar het niet waardig zijn in vers 6 (Catchpole 1993:301). De centurio associeert zich met mensen die 'onder gezag' (úrò k̇ं v. 8) staan (Catchpole 1993:301). Het participium 'hebbend' ( $\tilde{\varepsilon} \chi \omega v)$ dient toegevend te worden opgevat: 'hoewel ik soldaten en een slaaf heb die doen wat ik zeg, ben ik een man als zij, namelijk iemand die onder het gezag van iemand anders staat' (v. 8; Catchpole 1993:301). Ten slotte noemt de centurio Jezus 'Heer' (v. 6; Catchpole 1993:301). Het voorafgaande betekent dat de centurio in een menselijke context een man van gezag is, maar in vergelijking met de Heer Jezus de mindere is (Catchpole 1993:303). De honderdman is dus niet bedoeld als voorbeeld van een goede Romein, maar van een man van gezag die Jezus als de ware Heer erkent. Jezus als de ware Heer erkennen betekent dat men anderen, zoals de keizer, niet als zodanig erkent.

Het tweede voorbeeld van Frenschkowski (2002:113) is Q/Mattëus 5:41: 'degene die jou dwingt één mijl met hem mee te gaan, ga twee mijl met hem mee.' Volgens Frenschkowski (2002:113) veronderstelt dit een zekere mate van gehoorzaamheid aan het Romeinse gezag (zie ook Schottroff 1975:219). Het zou hier namelijk gaan om het recht van angaria, het recht van een Romeinse soldaat om niet-militairen diensten te laten verrichten (Frenschkowski 2002:113; zie ook Ebner 2000:124-126). Ook hier is het, echter, de vraag of de bedoelde soldaat waarmee men een tweede mijl mee zou moeten gaan een heidense Romein is. Verder gaat voor $Q$ gehoorzaamheid aan God (Q 12:4-5) en Jezus ( $Q$ 6:46) boven gehoorzaamheid aan de autoriteiten. De oproep in Q 12:4-5 wijst duidelijk in deze richting:

Wees niet bang voor degenen die het lichaam doden, maar niet in staat zijn de ziel te doden: maar vrees hem die zowel de ziel als het lichaam in Gehenna doden kan.

Geloof(sverkondiging) mag niet zwichten voor vervolging (Schröter 1997:355; Horsley 1999c:272-273). Voor vervolgers hoeft men niet bang te zijn, alleen voor God. Hoewel Q niet dezelfde terminologie gebruikt, vertoont de strekking van de tekst gelijkenis met die van Handelingen 5:29, dat men meer verantwoording verschuldigd is aan God dan aan mensen. Bovendien gaat het er in Q/Matteüs 5:41, evenals in de omliggende verzen $(Q 6: 29,30)$, waarschijnlijk om dat men zich niet moet beroepen op de 'rechten' die men theoretisch gezien heeft (Piper 2000:219, 250; Kloppenborg 2000:194). Het is dus een oproep zich niet te verzetten (Wink 1988:218); een positieve opvatting over Romeinen kan men er niet uit opmaken.

Uit de visie van $\mathrm{Q}$ op de gewenste houding tegenover de wereldlijke macht spreekt geen positiviteit, maar eerder een zekere gelatenheid. Zo stelt Q 6:22-23 dat zij die vervolgd worden vanwege hun geloof in de Mensenzoon in de hemel beloond zullen worden (Kloppenborg 1987:173; maar vgl. Neyrey 1995:145). Het lot van de volgelingen van Jezus wordt hierbij vergeleken met dat van de vroegere profeten (v. 23; Kloppenborg 2000:370; Schmithals 2004:435; vgl. Jervis 2002). De verwijzingen in $Q$ naar vervolging en verzet $(Q$ 
$6: 22-23 ; 11: 49-50 ; 12: 4-5 ; 13: 34-35)$ en naar het kruis (14:27) moeten waarschijnlijk worden verstaan in het licht van Jezus' dood, waarbij het lot van Jezus met dat van zijn volgelingen is verbonden (Kloppenborg 2000:371; Labahn 2004:418; vgl. Horsley 1999d:279-283; Frenschkowski 2000:26-27). Jezus volgen, betekent bereid zijn trouw te zijn tot in de dood (Seeley 1991; Schröter 1997:409; vgl. Frenschkowski 2000: 28-29), waarna vindicatie door God zal volgen. Van verzet is dus geen sprake. De tekst roept juist op je vijanden lief te hebben, te bidden voor wie je vervolgen, je andere wang toe te keren aan degene die je heeft geslagen, anderen te behandelen zoals je wilt dat ze jou behandelen en te houden van wie niet van jou houden (Q 6:27-32). Q roept de geadresseerden op af te zien van geweld, verzet of vergelding (vgl. Horsley 1999b:220), dat is, tot een vorm van 'demonstratieve weerloosheid' (Ebner 2000:126, 127, 129, 130, 131, 140). Vooral de verwijzing naar het kruis in Q 14:27 brengt de tekst in verband met Rome. Het kruis representeert het 'conflict' tussen de Jezusbeweging en de (Romeinse) overheid (zie ook Horsley 1999c:272-273). De Romeinse macht wordt niet voorgesteld als iets positiefs, maar als een bestaand kwaad waar men nu eenmaal niet omheen kan.

\section{$Q$ en de keizercultus}

\section{Alleen God vereren}

$Q$ gaat vrij duidelijk in tegen de pretenties die met de keizerlijke cultus waren verbonden. Met de 'keizercultus' wordt het geheel van praktijken en rituelen die met de verering van de keizer samenhingen bedoeld zoals dit in het Romeinse Rijk in de eerste eeuw (de periode waarin $Q$ moet zijn ontstaan) bestond (bv. Gradel 2002). In Q 4:5-8 stelt de duivel Jezus op de proef door te beloven hem alle koninkrijken van de wereld te zullen geven onder de voorwaarde dat hij voor hem neerbuigt. Jezus antwoordt hem vervolgens: 'Er staat geschreven: "Buig neer voor de Heer uw God en dien alleen hem".' De passage spreekt weliswaar niet expliciet over de verering van de keizer, maar dit lijkt wel degelijk te worden verondersteld. Het neerbuigen voor de duivel wordt immers geassocieerd met de wereldlijke macht. De wereldlijke macht wordt gezien als het domein van de duivel. Daar komt bij dat de aan Jezus toegeschreven uitspraak, dat het op basis van de Schrift vanzelfsprekend is dat men alleen voor de Heer God neerbuigt en alleen hem dient, impliceert dat men anderen, dus ook de keizer, niet mag vereren. De boodschap dat alleen God vereerd mag worden, kan moeilijk los van enige politieke inhoud worden gezien (vgl. Tuckett 1992:502, n. 104).

Sommige onderzoekers menen dat deze tekst verwijst naar concrete, historische gebeurtenissen. Zo heeft G. Theißen (1989:215-232) betoogd dat de passage refereert aan de aanval van Gaius Caligula op het joodse monotheïsme in het jaar 40, omdat de drie belangrijkste elementen van het verhaal naar deze Romeinse keizer zouden verwijzen. Volgens Theißen verwijst de prosternatie voor de wereldleider naar Caligula, omdat dit gebruik in Romeinse kringen vóór het keizerschap van Caligula niet voorkwam. Verder zou de macht om koninkrijken te schenken verwijzen naar het gegeven dat
Caligula in het oosten zes koningen aanstelde. Ten slotte zou de poging van de duivel om Jezus voor hem te laten buigen verwijzen naar de poging van Caligula van zichzelf een beeld op te richten in de tempel van Jeruzalem en dat te laten aanbidden. Verschillende onderzoekers hebben terecht geconcludeerd dat het twijfelachtig is dat deze drie elementen naar keizer Caligula verwijzen (Tuckett 1992: 501-502, n. 103; Myllykoski 1996:155-175; Allison 1997:51; Kloppenborg 2000:83; Labahn 2004:415). Geen van de door Theißen aangehaalde bronnen (Suetonius, Vitellius 2; Philo, Legatio 116-117, 352; Cassius Dio 59.24.4; 59.27.1) bewijzen dat Caligula de prosternatie heeft geïnitieerd (Myllykoski 1996:160). Verder wijst de uitdrukking 'alle koninkrijken van de wereld' erop dat de tekst niet zozeer over één bepaalde Romeinse keizer in het bijzonder gaat, maar over de wereldlijke macht in het algemeen (waarbij vooral aan het Romeinse gezag gedacht zal zijn). Ten slotte is de stelling dat men alleen de Heer God mag aanbidden eenvoudigweg een wijdverbreide bijbelse opvatting (monolatrie).

Welbeschouwd bevat de tekst geen gegevens die duidelijk en expliciet in de richting van een bepaalde keizer wijzen. Het is weliswaar mogelijk of zelfs waarschijnlijk dat de aanleiding tot het schrijven van de passage (of in elk geval tot het opnemen van de passage in de verzameling uitspraken) gelegen is geweest in ervaringen van de auteur(s) met de wereldlijke heerschappij en de keizercultus, maar hierover komt men geen enkele bijzonderheid, niets concreets te weten. Daar komt bij dat de vraag of de passage wel of niet in een historische context te plaatsen is, voor de betekenis van de tekst niet bepalend is. De heersende macht en keizercultus zijn niets meer en niets minder dan de aanleiding geweest voor het overdenken van de gewenste houding van gelovigen tot de wereldlijke overheid en de verering van de keizer. De $Q$ passage geeft hierop als antwoord dat de wereldlijke macht het domein van de duivel is en dat men volgens de Schrift alleen God mag vereren. De historische achtergrond blijft onbekend en maakt voor de betekenis van de passage geen verschil.

Ook de opvatting dat alleen God als Heer gediend mag worden (Q 16:13) doet per definitie af aan het gezag van de keizer (Frenschkowski 2002:112-114; zie ook, m.b.t. Matteüs: Carter 2000:42-43; m.b.t. Marcus: Guttenberger 2002:119; m.b.t. Lucas: Meiser 2002:190; m.b.t. Johannes: Richey 2007:64-65; en m.b.t. Paulus [1 Thess]: Donfried 1997:217). Sterker nog, de veronderstelling dat alleen God Heer is, impliceert dat anderen, dus ook de keizer, dit niet zijn. Q ondermijnt het gezag en de vermeende goddelijkheid van de keizer. De legitimiteit van 'de' keizercultus wordt hiermee verworpen.

\section{Gods superieure macht}

Ook het beeld van Gods almacht dat Q naar voren brengt, doet afbreuk aan de pretenties van de keizercultus. Zo is het dankgebed in Q 10:21 gericht aan de 'Vader, Heer van hemel en aarde'. Hieruit blijkt dat het God is die zowel in de hemel als op aarde het gezag heeft. Gods macht is daarmee 
superieur ten opzichte van alle andere heerschappijen. Het beeld van Gods almacht impliceert dat alle andere machten ondergeschikt zijn aan God. Daarmee wordt de opvatting dat de macht van de keizer door de goden is gewild ondergraven. In de literatuur over $Q$ wordt van mogelijke politieke implicaties van Q 10:21 veelal geen gewag gemaakt (bv. Catchpole 1993; Schröter 1997:204; ed. Lindemann 2001; Frenschkowski 2002:103; eds. Robinson, Heil \& Verheyden 2005).

\section{Gods koninkrijk}

$Q$ gaat, ten slotte, uit van de uiteindelijke ondergang van de bestaande wereldorde. Gods koninkrijk kome (Q 11:2b). De komst van Gods koninkrijk zal de bestaande wereld figuurlijk gezien op zijn kop zetten. Gods rijk is, namelijk, voor de armen ( $Q$ 6:20) en kleinen ( $Q$ 7:28) en heeft de zieken zelfs al bereikt ( $Q$ 10:9). Jezus zal het graan verzamelen en het kaf laten verbranden (Q 3:17; Webb 1991). De eschatologische verwachting dat de bestaande wereldorde zal worden vervangen door (of opgenomen in, aldus Betz 1992:222) Gods koninkrijk botst met de veronderstellingen van de keizercultus, volgens welke het keizerlijke gezag goddelijk gesanctioneerd is (bv. Carter 2000:39-43). Het idee van de goddelijke sanctionering van het keizerschap komt bijvoorbeeld tot uitdrukking in Seneca, De clementia 1.1.2, waar Nero zegt:

egone ex omnibus mortalibus placui electusque sum, qui in terris deorum uice fungere?

Is het niet dat ik van alle stervelingen genade heb gevonden en uitverkoren ben om op aarde te dienen als afgezant van de goden? (ed. Braund 2009:94)

De realisatie van Gods koninkrijk zal niet zonder slag of stoot plaatsvinden. In Q 12:51 zegt Jezus: 'Ik ben niet gekomen om vrede te brengen, maar een zwaard ( $\left.\mu \alpha \alpha_{\alpha} \alpha \iota \rho \alpha\right)$.' De tekst geeft aan dat met de komst van Jezus geen tijd van eschatologische vrede is aangebroken, maar een tijd vol problemen (Hahn 2002:153; Allison 1999a:299). Er is geen aanwijzing dat gelovigen een actieve verzetsrol wordt toebedeeld in een conflict met de Romeinen (vgl. Brandon 1967:20, n. 4, 320-321, n. 2, 1971:453). Het gaat ook niet om het gebruik van geweld uit zelfverdediging in een tijd van vervolgingen (tegen Cullmann 1956:21-22). Het zwaard staat symbool voor de eindstrijd voorafgaand aan het laatste oordeel (Black 1984:293-294). De wijze waarop Q de realisatie van Gods koninkrijk verwacht, geeft aan dat niet de gelovigen, maar God de aanzet zal geven. 'Stil maar, wacht maar, alles wordt nieuw ...'

\section{Q's opvattingen over de wereldlijke macht en de keizercultus in een vergelijkend perspectief De wereldlijke macht}

De vraag dient zich aan waar $Q$ qua opvattingen over de autoriteiten staat in vergelijking met de geschriften van het Nieuwe Testament. Een eerste vraag is hoe Q's opvattingen over het contrast tussen het koninkrijk van God en dat van de keizer zich verhouden tot die in de canonieke evangeliën (Matt 22:21; Marc 12:17; Luc 20:25; Joh 18:36). Dit contrast wordt doorgaans dualistisch en apologetisch opgevat. Gods rijk en het Romeinse rijk zouden worden voorgesteld als twee naast elkaar bestaande machten. Dit zou christenen in staat stellen zich te doen voorkomen als burgers van twee werelden in plaats van als vijanden van de regering (Mastin 1973:363; Brennecke 1997:50). Andere onderzoekers verwerpen een apologetische lezing en betogen dat de Romeinse macht wordt voorgesteld als ondergeschikt aan de macht van God die heerst over de hemel en de aarde (Meeks 1967:64; Pesch 1977:227-228; Richey 2007:163). Voor Q geldt het laatste. Uit de associatie van de wereldlijke macht met de duivel spreekt duidelijk een kritische distantie ten opzichte van de overheid (Q 4:5-6; 11:18, 20). Verder wordt God als Heer van hemel én aarde voorgesteld (Q 10:21).

Q neemt een middenpositie in (Frenschkowski 2002:113) tussen onvoorwaardelijke onderwerping en bijna-revolutie. Het eerste is wel beweerd van 1 Petrus $2-3$ en Titus 3:1 (Thurén 2002:215 met n. 1, 226). Het tweede van het boek Openbaring (bv. Collins 1983). Enerzijds is in Q van proRomeinse sentimenten geen sprake. $Q$ is kritisch over de status quo (Q 4:5-8; 11:18, 20) en alleen God en Jezus worden als Heer en Meester erkend; de keizer niet (bv. Q 6:46; 7:6; 16:13). Anderzijds is $Q$ alles behalve revolutionair. Van een oproep tot verzet is geen sprake. Vooropgesteld dat $Q$ niet zomaar met een tekst uit een andere periode mag worden vergeleken, kan worden opgemerkt dat de houding van $\mathrm{Q}$ dichtbij die van Justinus Martyr komt, maar op ten minste één punt verschilt. Justinus schrijft, namelijk, dat christenen de koningen en heersers op aarde erkennen, alleen God vereren en zich verlaten op het laatste oordeel als de overheid geen rekening met hen houdt:

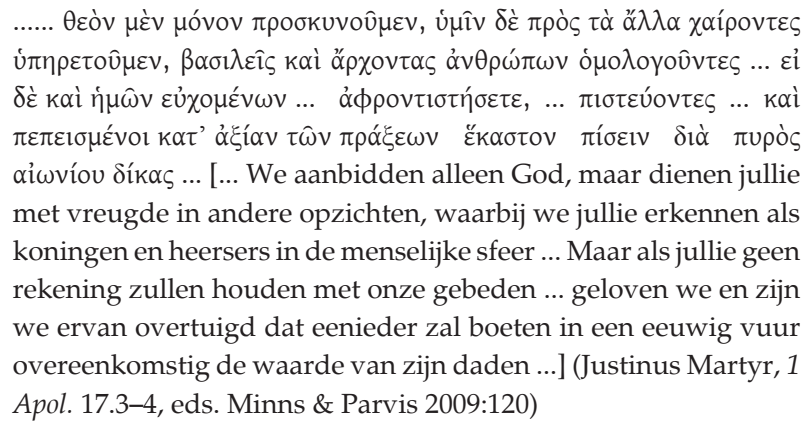

Anders dan Justinus, erkent $Q$ de wereldlijke heersers niet (vgl. Q 10:21), maar uit de overeenkomsten op het punt van de verering van God (vgl. Q 4:8), waarbij hetzelfde jargon wordt gebruikt ( $\pi \rho \circ \sigma \kappa v v \varepsilon ́ \omega)$, en op het punt van het zich verlaten op Gods oordeel (vgl. Q 3:17; zie ook Kirk 1998:8) blijkt dat onder christenen een kritische, passieve houding ten opzichte van de wereldlijke macht vanaf de eerste tot diep in de tweede eeuw heeft voortbestaan.

Tussen Q's opvattingen over de overheid en Q's houding ten opzichte van de overheid zit een zekere spanning. Uit de opvattingen spreekt immers een zekere vijandigheid, maar uit de gepropageerde houding niet. R. Piper (1995:60) spreekt 
van een 'diepgeworteld wantrouwen' jegens de overheid. Over dit wantrouwen zegt Piper (1995:63) dat het niet zozeer direct tegen Rome gericht hoeft te zijn, maar eerder tegen de locale autoriteiten in Galilea. Het wantrouwen zou zo sterk zijn geweest dat men koos voor vrijwillige overgave (Piper 1995:63). Hierbij dient te worden opgemerkt dat de vanuit het westen aangestuurde locale overheid door $\mathrm{Q}$ toch zeker met Rome geassocieerd zal zijn. Verder is het niet aannemelijk dat de houding van 'vrijwillige overgave' uit wantrouwen voortkwam. Je vrijwillig overgeven aan wie je niet vertrouwt, is niet bepaald een te verwachten menselijke reactie.

De reden zal waarschijnlijk pragmatisch zijn geweest. Van enige 'tactische' reden kan in elk geval geen sprake zijn: van voorzichtigheid of terughoudendheid, bijvoorbeeld uit angst voor vervolgingen, geeft de tekst geen blijk. In zowel politiek als religieus opzicht wordt de keizer vrij duidelijk bekritiseerd. Overigens kon men best kritisch over de keizer zijn zonder direct vervolgd te worden. Seneca is hiervan een bekend voorbeeld. Zo schrijft hij over keizer Claudius:

deus fieri vult: parum est quod templum in Britannia habet, quod $<$ hunc $>$ nunc barbari colunt et ut deum orant ...

Hij wil een god worden: is hij niet tevreden dat hij een tempel in Brittannië heeft, dat de barbaren hem vereren en hem als een god aanbidden ...? (Seneca, Apocolocyntosis 8.3, ed. Lund 1994:42)

Wellicht was het niet de bedoeling dat $\mathrm{Q}$ zou overkomen als een anti-Romeinse tekst, maar de belangrijkste reden niet tot revolutie op te roepen was waarschijnlijk de volgende. Als relatief kleine groep was men eenvoudigweg niet bij machte de politieke situatie te veranderen. In opstand komen tegen de autoriteiten had dan ook geen enkele zin. Dat $Q$ de eigen groep als van beperkte omvang zag, blijkt wel uit de uitspraak in Q 10:2: 'de oogst is groot, maar arbeiders zijn er weinig.' In deze situatie ligt het meer voor de hand een realist dan een revolutionair te zijn.

J.C. Scott, R.A. Horsley en anderen lezen in Q toch een min of meer 'verborgen verzet' tegen de regeringsmacht (Horsley 2006a:22, 2006b:153, 155). Vanuit het idee dat Q gezien moet worden als een 'publieke bekendmaking van een verborgen transcript', menen zij dat de tekst een dissidente, morele tegencultuur representeert die onder de lezers of toehoorders vertrouwen wekt in een immanente realisatie van een revolutionaire, nieuwe sociale orde ten koste van de huidige machthebbers (Horsley 2006a:20-22, 2006b:154, 156). Het voorliggende artikel sluit voor een belangrijk deel aan bij het idee van een 'verborgen transcript', maar heeft toch een belangrijk bezwaar tegen bovengenoemde opvattingen. Als in Q daadwerkelijk sprake zou zijn van een 'niet-langerzo-verborgen mobilisatie' (Horsley 2006a:22), dat is, actief verzet, dan zou men verwachten dat zowel de opvattingen over de machthebbers als de gepropageerde houding tot de machthebbers verzet impliceren. Van het laatste is, evenwel, geen sprake. $\mathrm{Q}$ wordt niet gekenmerkt door actief verzet.

\section{De keizercultus}

Het is duidelijk dat $Q$ de verering van de keizer niet accepteert. De opvatting dat alleen God of Jezus als Heer mogen worden erkend (bv. Q 4:5-8; 7:6), impliceert dat dit voor anderen die hierop aanspraak menen te kunnen maken niet geldt, dus ook niet voor de keizer. Verder onderstreept Jezus' gebed tot de 'Vader, Heer van hemel en aarde' (Q 10:21) dat alle andere heerschappijen ondergeschikt zijn aan die van God. Ten slotte ondermijnt de eschatologische verwachting dat de bestaande wereldorde zal worden vervangen door Gods koninkrijk het idee dat het keizerlijke gezag goddelijk gesanctioneerd is $(\mathrm{Q}$ $6: 20 ; 7: 28 ; 10: 9 ; 11: 2 b ; \operatorname{vgl} .3: 17)$.

Het voorafgaande roept de vraag op, of $Q$ alleen de keizercultus als zodanig verwerpt, of dat er meer aan de hand is. Het is van belang op te merken dat $Q$ zich alleen tot de eigen groep richt, niet tot buitenstaanders die aan de keizercultus meedoen. De wijze waarop Q de kritiek op de keizercultus formuleert, geeft aan dat de auteur niet zozeer leden van de eigen groep erop aanspreekt dat ze aan de cultus deelnemen, maar benadrukt dat gelovigen zich daarvan dienen te onthouden. Het is eerder een waarschuwing tegen participatie dan een veroordeling van een onder groepsleden gangbaar geworden gebruik. Als zodanig functioneert de kritiek op de keizercultus als bevestiging en versterking van de identiteit van de gemeenschap. 'Wij doen zoiets niet.' $\mathrm{Q}$ richt zich op de eigen groep en distantieert zich van de verering van de keizer en van de wereldlijke macht in het algemeen.

Het perspectief van waaruit Q's opvattingen over de wereldlijke macht en over de keizercultus gezien moeten worden, hangt samen met de datering van de tekst. Binnen de context van dit artikel kan over het moeilijke probleem van datering weinig met zekerheid worden vastgesteld. Het nu volgende is dan ook slechts een korte schets van de verschillende opties. Rond het jaar 50 (bv. Manson 1949:20; Horsley 2006a:19; vgl. Lührmann 1969:88) zouden Q's opvattingen met de heersende stroming zijn overeengekomen. In de jaren zestig en zeker in de periode 66-70 (bv. Frenschkowski 2002:95, 113; vgl. Hoffmann 1992:451-453, 456) zou Q niet tot de hoofdstroom hebben behoord. In het laatste geval zou de tekst eigenlijk een vrij zinloze boodschap hebben uitgedragen. Als $Q$, ten slotte, na de opstand tot een tekst is samengebracht (bv. Myllykoski 1996:199; Fleddermann 2005:159), kan de tekst gelezen worden als een poging om een kritisch geluid tegen het Romeinse gezag gaande te houden.

\section{Conclusie}

Samenvattend kan het volgende worden geconcludeerd. Q staat vijandig tegenover de wereldlijke overheid ( $Q$ 4:5-6; 11:18, 20), erkent het Romeinse (vgl. Q 14:27) gezag niet (Q 10:21) en verwerpt de legitimiteit van de verering van de keizer (Q 4:7-8). De tekst richt zich volledig op God (bv. Q 4:8, $12 ; 10: 21 ; 16: 13)$, Jezus (bv. 7:6) en de vervolmaking van Gods koninkrijk (Q 6:20; 7:28; 10:9; 11:2b). Tegelijkertijd wordt het Romeinse Rijk gezien als een realiteit waarmee de religieuze gemeenschap van beperkte omvang (Q 10:2) het nu eenmaal moet doen. De gepropageerde kritische distantie bestaat niet 
uit verzet, maar uit het zich op God verlaten (Q 6:22-23, 27-32; 12:4-5). Bron $Q$ geeft daarmee blijk van een realiteitszin die sommigen bij gelovigen haast voor onmogelijk houden.

\section{Tegenstrijdige belangen}

De auteur verklaart geen financiële of persoonlijke belangen te hebben die hem ongepast kunnen hebben beïnvloed bij het schrijven van dit artikel.

\section{Literatuurverwijzingen}

Allison, D.C., 1997, The Jesus tradition in Q, Trinity, Harrisburg, PA.

Allison, D.C., 1999a, 'Q 12:51-53 and Mark 9:11-13 and the messianic woes', in B. Chilton \& C.A. Evans (eds.), Authenticating the words of Jesus, pp. 289-310, Brill, Leiden/Boston/Köln.

Allison, D.C., 1999b, 'Behind the temptations of Jesus: Q 4:1-13 and Mark 1:12-13', in B. Chilton \& C.A. Evans (eds.), Authenticating the activities of Jesus, pp. 195-213, Brill, Leiden/Boston/Köln.

Betz, H-D., 1992, 'Eschatology in the Sermon on the Mount and the Sermon on the Plain', in H-D. Betz (ed.), Synoptische Studien: Gesammelte Aufsätze, vol. 2, pp. 219-229, Mohr Siebeck, Tübingen.

Black, M., 1984, “Not peace but a sword': Matt 10:34ff; Luke 12:51ff', in E. Bammel \& C.F.D. Moule (eds.), Jesus and the politics of his day, pp. 287-294, Cambridge \& C.F.D. Moule (eds.), Jesus and the politics of his day, pp. 287-294, Cambridge
University Press, Cambridge. http://dx.doi.org/10.1017/CBO9780511554834.018

Brandon, S.G.F., 1967, Jesus and the Zealots: A study of the political factor in primitive Christianity, Manchester University Press, Manchester.

Brandon, S.G.F., 1971, '”Jesus and the Zealots": A Correction', New Testament Studies 17, 453. http://dx.doi.org/10.1017/S0028688500024140

Braund, S. (ed.), 2009, Seneca, De clementia, Oxford University Press, Oxford.

Brennecke, H.C., 1997, ',An fidelis ad militiam converti possit'? [Tertullian, de idolatria 19,1]. Frühchristliches Bekenntnis und Militärdienst im Widerspruch?', in D. Wyrwa (ed.), Die Weltlichkeit des Glaubens in der Alten Kirche: Festschrift für Ulrich Wickert zum siebzigsten Geburtstag, pp. 45-100, De Gruyter, Berlin/New York.

Burchard, C., 1998, 'Jesus für die Welt. Über das Verhältnis von Reich Gottes und Mission', in C. Burchard, Studien zur Theologie, Sprache und Umwelt des Neuen Testaments, ed. D. Sänger, pp. 51-64, Mohr Siebeck, Tübingen.

Carter, W., 2000, Matthew and the margins: A socio-political and religious reading, Sheffield Academic Press, Sheffield.

Catchpole, D.R., 1993, 'Faith', in The quest for Q, pp. 280-308, T\&T Clark, Edinburgh.

Cliteur, P., 2010, Het monotheïstisch dilemma of De theologie van het terrorisme, De Arbeiderspers, Amsterdam/Antwerpen.

Collins, A.Y., 1983, 'Persecution and vengeance in the Book of Revelation', in D. Hellholm (ed.), Apocalypticism in the Mediterranean World and the Near East, pp. 729-749, Mohr Siebeck, Tübingen.

Cullmann, O., 1956, Der Staat im Neuen Testament, Mohr Siebeck, Tübingen.

Donfried, K.P., 1997, 'The imperial cults of Thessalonica and political conflict in 1 Thessalonians', in R.A. Horsley (ed.), Paul and empire: Religion and power in Roman imperial society, pp. 215-223, Trinity, Harrisburg, PA.

Draper, J.A., 1999, 'The announcement and testing of the prophet', in R.A. Horsley \& J.A. Draper, Whoever hears you hears me: Prophets, performance and tradition in Q, pp. 250-259, Trinity, Harrisburg, PA.

Ebner, M., 2000, 'Feindesliebe - ein Ratschlag zum Überleben? Sozial- und religionsgeschichtliche Überlegungen zu Mt 5,38-47 par Lk 6,27-35', in J.Ma. Asgeirsson, K. De Troyer \& M.W. Meyer (eds.), From quest to Q: Festschrift James M. Robinson, pp. 119-142, Leuven University Press/Peeters, Leuven.

Fleddermann, H.T., 2005, Q: A reconstruction and commentary, Peeters, Leuven/Paris/ Dudley, MA.

Frenschkowski, M., 2000, 'Welche biographischen Kentnisse von Jesus setzt die Logienquelle voraus? Beobachtungen zur Gattung von $Q$ im Kontext antiker Spruchsammlungen', in J.Ma. Asgeirsson, K. De Troyer \& M.W. Meyer (eds.), From quest to Q: Festschrift James M. Robinson, pp. 3-42, Leuven University Press/ quest to Q: Festsch
Peeters, Leuven.

Frenschkowski, M., 2002, "Kyrios in context: Q 6:46, the emperor as "lord", and the political implications of Christology in $\mathrm{Q}^{\prime}$, in M. Labahn \& J. Zangenberg (eds.),
Zwischen den Reichen: Neues Testament und römische Herrschaft: Vorträge auf der ersten Konferenz der European Association for Biblical Studies, pp. 95-118, Francke, Tübingen/Basel.

Gradel, I., 2002, Emperor Worship and Roman Religion, Oxford University Press, Oxford.

Guttenberger, G., 2002, 'Why Caesarea Philippi of all sites? Some reflections on the political background and implications of Mark 8:27-30 for the Christology of Mark', in M. Labahn \& J. Zangenberg (eds.), Zwischen den Reichen: Neues Testament und römische Herrschaft. Vorträge auf der ersten Konferenz der European Association for Biblical Studies, pp. 119-131, Francke, Tübingen/Basel.

Hahn, F., 2002, The titles of Jesus in Christology: Their history in early Christianity, transl. H. Knight \& G. Ogg, 2nd edn., James Clarke, Cambridge.
Hieke, T., 2000, 'Schriftgelehrsamkeit in der Logienquelle: Die alttestamentlichen Zitate in der Versuchungsgeschichte Q 4,1-13', in J.Ma. Asgeirsson, K. De Troyer \& M.W. Meyer (eds.), From quest to Q: Festschrift James M. Robinson, pp. 43-71, \& M.W. Meyer (eds.), From quest to Q: Fests
Leuven University Press/Peeters, Leuven.

Hoffmann, P., 1992, 'QR und der Menschensohn: Eine vorläufige Skizze', in F. Van Segbroeck, C.M. Tuckett, G. Van Belle \& J. Verheyden (eds.), The four Gospels 1992: Festschrift Frans Neirynck, vol. 1, pp. 421-456, Leuven University Press/ 1992: Festschrift

Hoffmann, P., 1995, Tradition und Situation: Studien zur Jesusüberlieferung in der Logienquelle und den synoptischen Evangelien, Aschendorff, Münster.

Horsley, R.A., 1999a, 'Introduction', in R.A. Horsley \& J.A. Draper, Whoever hears you hears me: Prophets, performance and tradition in Q, pp. 1-13, Trinity, Harrisburg, PA.

Horsley, R.A., 1999b, 'The covenant renewal discourse: Q 6:20-49', in R.A. Horsley \& J.A. Draper, Whoever hears you hears me: Prophets, performance and tradition in Q, pp. 195-227, Trinity, Harrisburg, PA.

Horsley, R.A., 1999c, 'The kingdom of God as the renewal of Israel', in R.A. Horsley \& J.A. Draper, Whoever hears you hears me: Prophets, performance and tradition in Q, pp. 260-276, Trinity, Harrisburg, PA.

Horsley, R.A., 1999d, 'The renewal of Israel over against its rulers', in R.A. Horsley \& J.A. Draper, Whoever hears you hears me: Prophets, performance and tradition in Q, pp. 277-291, Trinity, Harrisburg, PA.

Horsley, R.A., 2006a, 'Introduction', in R.A. Horsley (ed.), Oral performance, popular tradition, and hidden transcript in $Q, \mathrm{pp} .1-22$, Society of Biblical Literature, Atlanta, GA.

Horsley, R.A., 2006b, 'Moral economy and renewal movement in Q', in R.A. Horsley (ed.), Oral performance, popular tradition, and hidden transcript in $Q$, pp. 143157, Society of Biblical Literature, Atlanta, GA.

Jacobson, A.D., 2000, 'Jesus against the family: The dissolution of family ties in the Gospel tradition', in J.Ma. Asgeirsson, K. De Troyer \& M.W. Meyer (eds.), From quest to Q: Festschrift James M. Robinson, pp. 189-218, Leuven University Press/ quest to Q: Fests
Peeters, Leuven.

Jervis, L.A., 2002, 'Suffering for the reign of God: The persecution of disciples in Q', Novum Testamentum 44, 313-332. http://dx.doi.org/10.1163/15685360260296218

Kirk, A., 1998, 'Upbraiding wisdom: John's speech and the beginning of Q (Q 3:7-9, 16-17)', Novum Testamentum 40, 1-16.

Kloppenborg, J.S., 1987, The formation of Q: Trajectories in ancient wisdom collections, Fortress, Philadelphia, PA.

Kloppenborg, J.S., 2000, Excavating Q: The history and setting of the Sayings Gospel, Fortress, Minneapolis, MN.

Labahn, M., 2004, 'Der Gottessohn, die Versuchung und das Kreuz. Überlegungen zum Jesusporträt der Versuchungsgeschichte in Q 4,1-13', Ephemerides theologicae lovanienses (ETL) 80, 402-422.

Lindemann, A., 1989, 'Die Versuchungsgeschichte Jesu nach der Logienquelle und das Vaterunser', in D-A. Koch, G. Sellin \& A. Lindemann (eds.), Jesu Rede von Gott und ihre Nachgeschichte im frühen Christentum: Beiträge zur Verkündigung Jesu und zum Kerygma der Kirche: Festschrift für Willi Marxsen zum 70. Geburtstag, pp. 91-100, Mohn, Gütersloh.

Lindemann, A. (ed.), 2001, The Sayings Source $Q$ and the historical Jesus, Leuven University Press/Peeters, Leuven/Paris/Sterling, VA

Lührmann, D., 1969, Die Redaktion der Logienquelle, Neukirchener, Neukirchen-Vluyn.

Lund, A.A. (ed.), 1994, L. Annaeus Seneca, Apocolocyntosis divi Claudii, Winter, Heidelberg.

Manson, T.W., 1949, The sayings of Jesus as recorded in the Gospels according to St Matthew and St. Luke arranged with introduction and commentary, 2nd edn. SCM, London.

Mastin, B.A., 1973, 'The imperial cult and the ascription of the title $\theta \varepsilon$ ó $\varsigma$ to Jesus (John $X X .28$ )', SE 6 (= TU 112), 352-365.

Meeks, W.A., 1967, The prophet-king: Moses traditions and the Johannine Christology Brill, Leiden.

Meiser, M., 2002, 'Lukas und die römische Staatsmacht', in M. Labahn \& J. Zangenberg (eds.), Zwischen den Reichen: Neues Testament und römische Herrschaft: Vorträge auf der ersten Konferenz der European Association for Biblical Studies, pp. 175auf der ersten Konferenz der Eur
193, Francke, Tübingen/Basel.

Minns, D. \& Parvis, P. (eds.), 2009, Justin, philosopher and martyr: Apologies, Oxford University Press, Oxford.

Myllykoski, M., 1996, 'The social history of Q and the Jewish war', in R. Uro (ed.), Symbols and strata: Essays on the Sayings Gospel Q, pp. 143-199, Finnish Exegetical Society, Helsinki/Vandenhoeck \& Ruprecht, Göttingen.

Neyrey, J.H., 1995, 'Loss of wealth, loss of family and loss of honour: The cultural context of the original makarisms in Q', in P.F. Esler (ed.), Modelling early Christianity: Social-scientific studies of the New Testament in its context, pp. 139158, Routledge, London/New York.

Pesch, R., 1977, Das Markusevangelium: II. Kommentar zu Kap. 8,27-16,20, Herder, Freiburg/Basel/Wien.

Piper, R.A., 1995, 'The language of violence and the aphoristic sayings in Q: A study of Q 6:27-36', in J.S. Kloppenborg (ed.), Conflict and invention: Literary, rhetorical, and social studies on the Sayings Gospel Q, pp. 53-72, Trinity, Valley Forge, PA.

Piper, R.A., 2000, 'Wealth, poverty, and subsistence in Q', in J.Ma. Asgeirsson, K. De Troyer \& M.W. Meyer (eds.), From quest to Q: Festschrift James M. Robinson, pp. 219-264, Leuven University Press/Peeters, Leuven. 
Räisänen, H., 2001, 'Exorcisms and the kingdom: Is Q 11:20 a saying of the historical Jesus?', in H. Räisänen, Challenges to biblical interpretation: Collected essays Jesus?', in H. Räisänen, Challenges to biblical
1991-2000, pp. 15-36, Brill, Leiden/Boston/Köln

Richey, L.B., 2007, Roman imperial ideology and the Gospel of John, Catholic Biblical Association of America, Washington, DC.

Robinson, J.M., Hoffmann, P. \& Kloppenborg, J.S. (eds.), 2001, The Sayings Gospel Q in Greek and English with parallels from the Gospels of Mark and Thomas, Peeters, Leuven/Paris/Sterling, VA.

Robinson, J.M., 2005, 'The Jesus of the Sayings Gospel Q', in J.M. Robinson, C. Heil \& J. Verheyden (eds.), The Sayings Gospel Q: Collected essays by James M. Robinson, pp. 375-388, Leuven University Press/Peeters, Leuven/Dudley, MA.

Schlosser, J., 2002, 'Les tentations de Jésus et la cause de Dieu', RevScRel 76, 403-425.

Schmithals, W., 2004, 'Zur Geschichte der Spruchquelle Q und der Tradenten der Spruchüberlieferung: Das siebenfache Wehe Lk 11,37-54par', in C. Breytenbach (ed.), Paulus, die Evangelien und das Urchristentum: Beiträge von und zu Walter Schmithals zu seinem 80. Geburtstag herausgegeben, pp. 429-454, Brill, Leiden/ Boston.

Schottroff, L., 1975, 'Gewaltverzicht und Feindesliebe in der urchristlichen Jesustradition. Mt 5,38-48; Lk 6,27-36', in G. Strecker (ed.), Jesus Christus in Historie und Theologie: Neutestamentliche Festschrift für Hans Conzelmann zum 60. Geburtstag, pp. 197-221, Mohr Siebeck, Tübingen.

Schottroff, L. \& Stegemann, W., 1978, Jesus von Nazareth - Hoffnung der Armen, Kohlhammer, Stuttgart.
Schröter, J., 1997, Erinnerung an Jesu Worte: Studien zur Rezeption der Logienüberlieferung in Markus, $Q$ und Thomas, Neukirchener, Neukirchen-Vluyn.

Seeley, D., 1991, 'Blessings and boundaries: Interpretations of Jesus' death in Q', Semeia 55, 131-146.

Theißen, G., 1989, Lokalkolorit und Zeitgeschichte in den Evangelien. Ein Beitrag zur Geschichte der synoptischen Tradition, Universitätsverlag, Freiburg, CH/ Vandenhoeck \& Ruprecht, Göttingen.

Thurén, L., 2002, 'Jeremiah 27 and civil obedience in 1 Peter', in M. Labahn \& J. Zangenberg (eds.), Zwischen den Reichen: Neues Testament und römische Herrschaft: Vorträge auf der ersten Konferenz der European Association for Biblical Studies, pp. 215-228, Francke, Tübingen/Basel.

Tuckett, C.M., 1992, 'The temptation narrative in Q', in F. Van Segbroeck, C.M. Tuckett, G. Van Belle \& J. Verheyden (eds.), The four Gospels 1992: Festschrift Frans Neirynck, vol. 1, pp. 479-507, Leuven University Press/Peeters, Leuven.

Tuckett, C.M., 1996, Q and the history of early Christianity: Studies on Q, T\&T Clark, Edinburgh.

Van de Poll, W., 2010, 'Gelovige moet zich aan wet houden', Trouw, geraadpleegd 30 november 2010, op http://www.trouw. nl/tr/nl/4324/nieuws/archief/article/ detail/1804974/2010/11/30/Gelovige-moet-zich-aan-wet-houden.dhtml.

Webb, R.L., 1991, 'The activity of John the Baptist's expected figure at the threshing floor (Matthew $3.12=$ Luke 3.17)', Journal for the Study of the New Testament 43, 103-111. http://dx.doi.org/10.1177/0142064X9101404307

Wink, W., 1988, 'Neither passivity nor violence: Jesus' third way', in D.J. Lull (ed.), Society of Biblical Literature 1988 Seminar Papers, pp. 210-224, Scholars, Atlanta, GA. 